\title{
Documentos
}

\section{CAMBIOS FENOTÍPICOS DEL EPITELO MAMARIO INDUCIDOS POR SU ENTORNO CELULAR}

\author{
Ricardo Cornejo U. ${ }^{1, a}$ \\ ${ }^{1}$ Departamento de Ciencias Básicas, Facultad de Medicina, Universidad de La Frontera, Temuco
}

aBiólogo celular, Ph.D.

\section{RESUMEN}

Se presenta una revisión bibliográfica relacionada con la funcionalidad de la matriz extracelular y sus distintos componentes en el sentido de gatillar y modular el proceso biológico de la diferenciación celular, con especial énfasis en los diferentes fenotipos adquiridos por las células pertenecientes al epitelio mamario de ratas mantenido en cultivo, como resultado de la inducción al proceso de diferenciación tanto en ausencia como en presencia de constituyentes de dicha matriz.

\section{PALABRAS CLAVE: Matriz extracelular, epitelio mamario, diferenciación celular}

\section{SUMMARY}

A literature review about extracellular matrix function and its different components in relation of triggering and modulating the cell differentiation process is presented. A special emphasis is stated on different acquired phenotypes of cultured mouse mammary epithelial cells as a result of induction cell differentiation with and without the cell matrix components.

\section{KEY WORDS: Extracellular matrix, mammary ephitelium, cellular differentiation}

El epitelio mamario es un tejido que sufre innumerables cambios generados por diferentes factores. Esta serie de eventos cíclicos modificadores de la estructura de este epitelio hace que este tejido sea blanco de numerosos estudios acerca de su diferenciación celular y tomando en consideración además que, como el resultado final de esta serie de modificaciones produce los componentes de la leche, ellos pueden ser, obviamente, utilizados como marcadores de la diferenciación en la glándula mamaria.

En los últimos veinte años, numerosos grupos de investigación han dedicado sus esfuerzos en identificar los eventos bioquímicos y morfológicos que desencadenan el proceso biológico de la dife- renciación en la glándula mamaria, habiéndose conseguido reunir variados datos que llevan al esclarecimiento parcial de este mecanismo. En este sentido, son hechos conocidos por la comunidad científica que el control de la diferenciación y del crecimiento en tejidos complejos, como la propia glándula mamaria, está determinado por: factores de crecimiento, estímulos hormonales y por la comunicación intercelular e interacciones entre las células y su matriz extracelular (MEC) $(1,2)$.

En el tejido epitelial, una zona especializada de la MEC denominada lámina basal, separa el tejido conjuntivo subyacente y puede ser distinguida por sus características morfológicas de doble estrato, conocidas como lámina rara y lámina den- 
sa. La lámina basal es producida por una variedad de tipos celulares, incluyendo células epiteliales y musculares, donde además de poseer un importante papel en la proliferación y migración celular, ella participa activamente en el establecimiento de la arquitectura del tejido y también constituye una barrera para el transporte de macromoléculas (3). Esta lámina basal está constituída por glicoproteínas y proteoglicanos que interactuan dando origen a un complejo supramolecular definido. La arquitectura de este complejo puede ser modificada por variaciones en su composición y por influencia de macromoléculas exógenas $(4,5)$.

Un modelo ideal para el estudio de las relaciones entre las señales de la MEC y el control funcional de un tejido, es el epitelio simple de la glándula mamaria de animales adultos, donde sus células presentan variaciones en su desarrollo durante la preñez, finalizando con una alta secreción de leche. La gran ventaja de este sistema es que, al ser mantenidas en cultivo, las células epiteliales mamarias mantienen su fenotipo diferenciado solamente por la estimulación hormonal y las condiciones específicas del sustrato (6).

Existen variadas evidencias indicando que la lámina basal desempeña un rol significativo en la regulación del fenotipo mamario in vivo, habiéndose demostrado que el epitelio alveolar de la glándula mamaria de roedores es rodeado completamente por una lámina basal y que su pérdida durante la involución se correlaciona con una regresión funcional de la glándula (7). Cuando son mantenidas en cultivo, teniendo como sustrato colágeno del tipo I, las células mamarias sintetizan y secretan proteínas de la leche solamente si una lámina basal endógena fuese previamente depositada (8).

La inhabilidad del epitelio mamario en funcionar adecuadamente en ausencia de la lámina basal sustenta el argumento de su envolvimiento en la inducción y en la mantención de la diferenciación epitelial. Además de este hecho, la función bioquímica de células cultivadas sobre sustratos de lámina basal, así como también sobre geles de colágeno no adherente, es acompañada por alteraciones cito-estructurales y por un notable incremento de las interacciones entre células adyacentes, por ello y con el objetivo de intentar precisar como estas interacciones pueden influenciar la especificidad de la expresión génica de los tejidos, se puede argumentar, entonces, que el medio ambiente local está incluido entre los factores inductores de la diferenciación de las células del epitelio mamario (6).
Con respecto a la diferenciación de células epiteliales mamarias mantenidas en cultivo y relacionadas con determinados sustratos, los investigadores del tema concluyen que, cuando el cultivo es realizado sobre un estroma exógeno de colágeno tipo I no adherente o sobre láminas basales obtenidas de células tumorales EHS (tumor de Englebreth-Holm-Swarm), las células de este epitelio mamario en cultivo adquieren o re-adquieren muchas propiedades o características de la diferenciación, entre las que se incluyen: morfología polarizada y/o polarización de los organelos subcelulares, aparecimiento de microvellocidades en la superficie apical, formación de la lámina basal, modificaciones sustanciales en el metabolismo de la glucosa y lactosa, acúmulo de RNAm de caseína y transferrina e incremento en la síntesis de las proteínas de la leche (9).

Mas aún, se ha demostrado que la presencia de láminas basales exógenas, derivadas por ejemplo de células EHS, influencia diferenciación específica también en otros tipos celulares como por ejemplo: células de Sértoli (10), células de Schwann (11), hepatocitos (12), células pulmonares alveolares tipo II (13), células endoteliales (14) y células del epitelio uterino (15), en todos estos sistemas se encontraron evidencias directas en el sentido que las láminas basales están involucradas en la citodiferenciación y por tanto, estos sistemas descritos permiten un abordaje del mecanismo celular por el cual la MEC puede alterar profundamente la expresión génica específica de los tejidos.

Otros autores sugieren que la inducción de funciones en las células mamarias cultivadas sobre un estroma de matriz se debe fundamentalmente a la síntesis y depósito de una lámina basal exógena más que a una interacción directa entre las células y el colágeno tipo I (8). Ocurre también que células cultivadas sobre geles libres, en ausencia de plástico y vidrio son capaces de sintetizar láminas basales intactas, con alto contenido de heparin-sulfato, colágeno tipo IV y laminina (16). En el mismo sentido, se demostró que cultivos primarios de células de epitelio mamario murino mantenidos en co-cultivo, tanto con adipocitos como con fibroblastos, son capaces de diferenciarse completamente, secretando beta caseína en respuesta a las inducciones con hormonas lactogénicas (17). Sin embargo, es necesario señalar que una línea de células epiteliales mamarias murinas normales, denominada $\mathrm{HC} 11$, derivadas de la línea COMMA 1D obtenida de la glándula mamaria de ratas $B A L B / c$ en la mitad de la preñez, se diferencia claramente de todos los tipos 
celulares antes señalados, puesto que, ellas no requieren de ningún componente de MEC exógeno y tampoco de co-cultivo con otros tipos celulares para responder a los estímulos de las hormonas que inducen secreción láctea (18).

Cuando estas células epiteliales mamarias de la línea HC11 son cultivadas en diferentes condiciones originan distintos tipos celulares denominados: HC11 GM correspondiente a células normales - proliferantes cultivadas con la inducción del Factor de Crecimiento Epidérmico (EGF) y por otro lado HC11 IM correspondiente a células diferenciadas, secretoras de beta caseína bajo inducción hormonal lactogénica después de estimulación con EGF. En este contexto, prolactina, hormona hipofisiaria que induce la transcripción de genes de proteínas de la leche, es responsable no solo por el aumento en la tasa de transcripción del RNA mensajero para beta caseína, sino también promueve acúmulo de este en el citoplasma, una vez que aumenta la vida media de este ácido nucleico (19). Del mismo modo, la hormona insulina posee funcionalidad anabólica, estimulando fuertemente la síntesis proteica en este tipo celular (20). Finalmente, hidrocortisona, hormona que pertenece a la clase de los glicocorticoides, induce poderosamente la diferenciación terminal de las células mamarias, actuando sinérgicamente con la prolactina en la inducción de la expresión del gen para beta caseína (21).

De igual manera, el EGF, un polipéptido de 6.045 D. purificado inicialmente de glándula salival y orina de ratón, es un agente mitogénico para muchas células epidérmicas y fibroblastos mantenidas in vitro, combinándose con un receptor específico tirosina quinasa a nivel de la membrana plasmática y fosforilando una serie de proteínas citoplasmáticas, desencadenando así la respuesta mitogénica (22). La adición de EGF al medio de cultivo, por lo menos 2 días es esencial para la producción de beta caseína por las células HC11 (23), fue demostrado también que cultivos de HC11 aptos para diferenciación son capaces de sintetizar grandes cantidad de beta caseína en presencia de hormonas lactogénicas por hasta 3 días después de retirado el EGF del medio de cultivo, luego de este tiempo las células secretan la proteína en menor cantidad. Este experimento prueba, entonces, que el EGF tiene un efecto de larga duración (24).

En consideración de la necesidad de tratamiento previo con el EGF por lo menos 2 días para la adquisición de competencia en respuesta al tratamiento hormonal aliada a la evidencia de que esta competencia no es rápidamente perdida, sugieren que el proceso este relacionado con la producción de MEC. De hecho algunos experimentos demuestran los efectos de la MEC sobre la inducción de beta caseína: las células HC11 son capaces de sintetizar grandes cantidades de beta caseína cuando son cultivadas sobre MEC derivada de células que han crecido en un medio con EGF; del mismo modo, niveles moderado de esta proteína son sintetizados cuando las HC11 son cultivadas sobre matriz derivada de células desarrolladas en un medio con insulina, y aún mas, pequeñas cantidades de caseína son producidas en células HC11 creciendo sobre superficie de plástico. Estos resultados sugieren que los elementos de la MEC que tienen su producción aumentada por el EGF son importantes para la producción de grandes cantidades de beta caseína (24).

Por otra parte, pero apuntando a la importancia de los elementos de la MEC en la diferenciación celular, las células $\mathrm{HC11}$ en fase de crecimiento secretan las glicoproteínas laminina y tenascina, tanto en presencia como en ausencia de EGF; cuando este factor está presente, las HC11 sintetizan pequeñas cantidades de laminina y tenascina, esta última aparece en vacuolas y también en el espacio extracelular como finas fibrillas. Laminina, por su parte aparece principalmente en pequeñas vacuolas. Cuando el EGF está ausente, laminina es hallada en vacuolas citoplasmáticas y en el espacio extracelular como fibrillas y tenascina mayoritariamente citoplasmática, constituyendo vacuolas. La presencia de estas vacuolas conteniendo MEC sugieren secreción y endocitosis de estas glicoproteínas (24).

Es necesario igualmente agregar que los cambios bioquímicos, estructurales y de integración funcional que caracterizan el proceso de diferenciación de estas células HC11 como resultado de la inducción con EGF y hormonas lactogénicas, se traduce en la aparición de la propiedad de sintetizar tanto beta caseína como un conjunto de filamentos citoplasmáticos cuyo diámetro oscila entre 8 y 12 nm, medidas clásicas que corresponden a filamentos intermediarios. El hecho que pertenecieran a células epiteliales y se agruparan en haces nos llevó a la hipótesis que se trataran de filamentos de citoqueratina, realizándose una reacción inmunológica y efectivamente constatar mediante la positividad de la reacción de la inmunoperoxidasa contra la proteína cioqueratina que, de hecho, los filamentos intermediarios presentes en las células HC11 IM, están constituídos de 
citoqueratina (25), por ende, tanto la síntesis de beta caseína como de filamentos intermediarios de citoqueratina pueden ser utilizados como marcadores de diferenciación en estas células del epitelio mamario mantenido en cultivo.

Sin embargo, un nuevo marcador de diferenciación en este tipo celular fue demostrado, evidenciándose que dos glicoproteínas asociadas a las membranas lisosomales denominadas LAMP-1 y LAMP-2 (Iysosomal associated membrane protein), presentan un importante incremento en su nivel de expresión como resultado del tratamiento con las hormonas lactogénicas. Este incremento se correlaciona directamente con un aumento en las fracciones volumétricas de los lisosomas los cuales fueron evaluados mediante métodos morfométricos durante el transcurrir de la diferenciación en estas células HC11, sugiriendo, entonces, que la biogénesis lisosomal es activada luego de la inducción lactogénica (26).

De acuerdo a los antecedentes presentados, aparece claramente visualizado el rol que la MEC y sus componentes desempeñan en la complejidad del proceso de diferenciación celular y específicamente en el tipo HC11, quedando evidentemente por precisar numerosos eventos que conllevan a la diferenciación de los tejidos.

\section{BIBLIOGRAFÍA}

1. Stoker A, Struli C, Martins-Green M, Bissell M. Designer microenvironments for the analysis of cell and tissue function. Curr Opin Cell Biol 1990; 2: 864-74.

2. Hood J, Cheresh D. Role of integrins in cell invasion and migratio. Nat Rev Cancer 2002; 2: 91-100.

3. McDonald J. Receptors for extracellular matrix components. Am J Physiol 1989; 257: 1331-7.

4. Yurchenco P, Schittny J. Molecular architecture of basement membrane. FASEB J 1990; 4: 1577-90.

5. Blobel C. Functional and biochemical characterization of ADAMs and their predicted role in protein ectodomain shedding. Inflamm Res 2002; 51: 83-84.

6. Streuli C, Bailey N, Bisesell M. Control of mammary epithelial differentiation: Basement membrane induces tissue-specific gene expression in the absence of cell-cell interaction and morphological polarity. $J$ Cell Biol 1991; 115: 1383-95.

7. Talhouk R, Chin J, Unemori E, Werb Z, Bissell M. Proteinases of the mammary glan: developmental regulation in vivo and vectorial secretion in culture. Development 1991; 112: 439-49.

8. Streuli C, Bissell M. Expression of extracellular matrix components is regulated by substratum. J Cell Biol 1990; 110: 1405-15.

9. Lee E, Parry G, Bissell M. Modulation of secreted proteins of mouse mammary epithelial cells by the collagenous substratta. J Cell Biol 1984; 98: 146-55.

10. Hadley M, Byers S, Suarez-Quian C, Kleinman H, Dym M. Extracellular matrix regulates Sértoli cell differentiatio, testicular cord formation, and germ cell development in vitro. J Cell Biol 1985; 101: 1511-22.

11. Carey D, Todd M, Rafferty C. Schwann cell myelimation: induction by exogenous basement membrane-like extracellular matrix. J Cell Biol 1986;102: 2254-63.

12. Schuetz E, Li D, Omiecinski C, Muller-Eberhard U, Kleinman H, Elswick B, Guzelian P. Regulation of gene expression in adult rat hepatocytes cultured on a basement membrane matrix. J Cell Biol 1988; 134: 309-23.

13. Shannon J, Mason R, Jennings S. Functional differentiation of alveolar type II epithelial cells in vitro: effects of cell shape, cell matrix interactions and cell-cell interactions. Biochem Biophys Acta 1987; 931: 143-56.

14. Kubota $Y$, Kleinman H, Martin G, Lawley T. Role of laminin and basement membrane in the morphological differentiation of human endothelial cells into capillary-like structure. J Cell Biol 1988; 107: 158998.

15. Glasse S, Julian J, Decker G, Tang J, Carson D. Development of morphological and functional polarity in primary cultures of inmature rat uterine epithelail cells. J Cell Biol 1988; 107: 2409-23.

16. Emerman J, Pitelka D. Maintenance and induction of morphological differentiation in dissociated mammary epithelium on floating collagen membranes. In Vitro 1977; 13: 316-28.

17. Levine J, Stockdale F. Cell-cell interactions promote mammary epithelial cell differentiation. J Cell Biol 1985; 100: 1415-22.

18. Ball R, Friis R, Schoenenberger C, Doppler W. 120 $\mathrm{kD}$ protein in a cloned mouse mammary epithelial cell line. EMBO J 1988; 7: 2089-95.

19. Guyette W, Matusik R, Rosen J. Prolactin-mediated transcriptional and post-transcriptional control of casein gene expression. Cell 1988; 17: 379-94.

20. Fawcet, D. Tratado de Histología. 11.ed. Interamericana-McGraw-Hill, 1987, 1981.

21. Doppler W, Groner B, Ball R. Prolactin and glucocorticoid hormones synergistically induce expression of transfected rat beta-casein gene promoter constructs in a mammary epithelial cell line. Proc Natl Acad Sci USA 1989; 86: 104-8.

22. Carpenter G, Cohen S. Epidermal Growth Factor. Biol Chem 1990; 265: 7709-12.

23. Taverna D, Groner B, Hynes N. Epidermal growth factor receptor, platelet-derived growth factor recptor, and c-erbB-2 receptor activation all promote growth but have distinctive effects upon mouse mammary epithelial cell differentiation. Cell Growth \& Differentiation 1991; 2: 145-54.

24. Hynes N, Taverna D, Chammas R. The effect of the extracellular matrix upon $\mathrm{HC} 11$ mammary epithelial 
cell differentiation. Ciencia e Cultura 1992; 44: 2536.

25. Cornejo R, Joazeiro P, Chammas R, Montes G, Caldini E. Morphometric differentiation of mammary epithelial cells in culture. Rev Chil Anat 1995; 13(1): 33-41.
26. Cella N, Cornejo R, Montes G, Hynes N, Chammas $R$. The lysosomal-associated protein LAMP-1 is a novel differentiation marker for $\mathrm{HC11}$ mouse mammary epithelial cells. Differentiation 1996; 61: 113-120. 